Provided for non-commercial research and education use. Not for reproduction, distribution or commercial use.

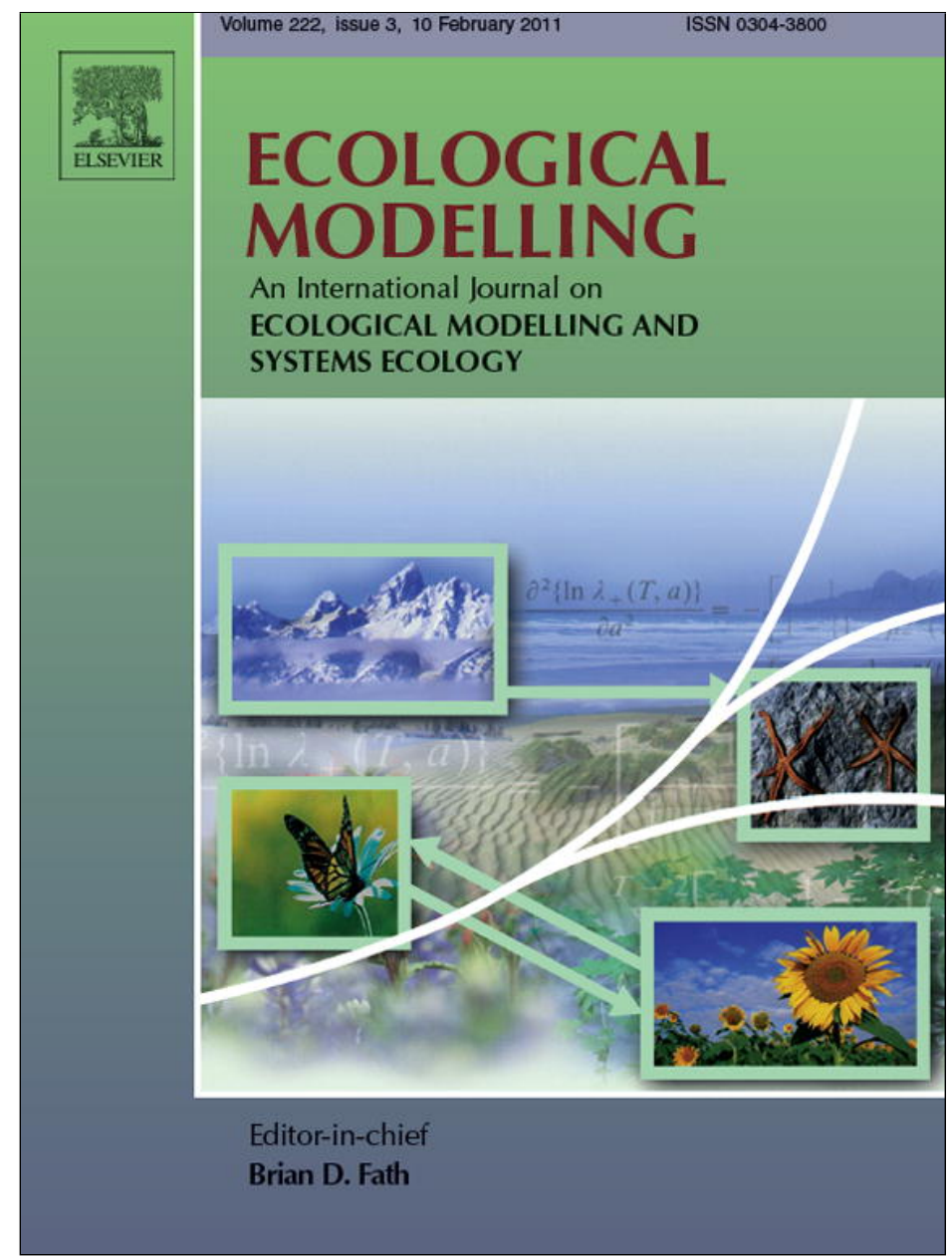

This article appeared in a journal published by Elsevier. The attached copy is furnished to the author for internal non-commercial research and education use, including for instruction at the authors institution and sharing with colleagues.

Other uses, including reproduction and distribution, or selling or licensing copies, or posting to personal, institutional or third party websites are prohibited.

In most cases authors are permitted to post their version of the article (e.g. in Word or Tex form) to their personal website or institutional repository. Authors requiring further information regarding Elsevier's archiving and manuscript policies are encouraged to visit:

http://www.elsevier.com/copyright 


\title{
Invasion and eradication of a competitively superior species in heterogeneous landscapes
}

\author{
S. Vuilleumier ${ }^{\mathrm{a}, \mathrm{b}, *}$, A. Buttler ${ }^{\mathrm{b}, \mathrm{c}}$, N. Perrin ${ }^{\mathrm{a}}$, J.M. Yearsley ${ }^{\mathrm{a}, \mathrm{d}}$ \\ a Department of Ecology and Evolution, University of Lausanne, CH-1015 Lausanne, Switzerland \\ ${ }^{\mathrm{b}}$ Laboratory of Ecological Systems-ECOS, Ecole Polytechnique Fédéral de Lausanne, CH-1015 Lausanne, Switzerland \\ c Swiss Federal Research Institute WSL, EPFL, Station 2, CH-1015 Lausanne, Switzerland \\ d School of Biological and Environmental Science, University College Dublin, Belfield, Dublin 4, Ireland
}

\section{A R T I C L E I N F O}

\section{Article history:}

Received 9 June 2010

Received in revised form

27 September 2010

Accepted 28 September 2010

\section{Keywords:}

Invasive species

Invasion

Eradication

Spatial heterogeneity

Metacommunity

Simulation model

\begin{abstract}
A B S T R A C T
The effect of heterogeneous environments upon the dynamics of invasion and the eradication or control of invasive species is poorly understood, although it is a major challenge for biodiversity conservation. Here, we first investigate how the probability and time for invasion are affected by spatial heterogeneity. Then, we study the effect of control program strategies (e.g. species specificity, spatial scale of action, detection and eradication efficiency) on the success and time of eradication. We find that heterogeneity increases both the invasion probability and the time to invasion. Heterogeneity also reduces the probability of eradication but does not change the time taken for successful eradication. We confirm that early detection of invasive species reduces the time until eradication, but we also demonstrate that this is true only if the local control action is sufficiently efficient. The criterion of removal efficiency is even more important for an eradication program than simply ensuring control effort when the invasive species is not abundant.
\end{abstract} (C) 2010 Elsevier B.V. All rights reserved.

\section{Introduction}

How an invasive species spreads and how it can be controlled are two important questions for the preservation of worldwide biodiversity (Manchester and Bullock, 2000; Marris, 2005; Holt et al., 2005; Simberloff, 2005; Melbourne et al., 2007; Levine, 2008). Answering the first question requires an understanding of species invasion dynamics, while tackling the second question requires an estimation of how control programs affect a species' abundance and eradication probability.

Invasion occurs through four main stages: transport, colonization, establishment and spread (Theoharides and Dukes, 2007). These processes occur in a spatially extended and often heterogeneous environment (Hastings et al., 2005; Seno and Koshiba, 2005). Both spatial extent and heterogeneity are recognized as drivers of invasion and coexistence within communities (Chesson, 2000; Mouquet and Loreau, 2002; Shea and Chesson, 2002; Melbourne et

\footnotetext{
* Corresponding author at: Department of Ecology and Evolution, University of Lausanne, CH-1015 Lausanne, Switzerland. Tel.: +41 21692 4176; fax: +41216924165.

E-mail addresses: severine.vuilleumier@unil.ch (S. Vuilleumier), alexandre.buttler@epfl.ch (A. Buttler), nicolas.perrin@unil.ch (N. Perrin), jon.yearsley@ucd.ie (J.M. Yearsley).
}

al., 2007). But in general there is a lack of research into the overall effect of heterogeneous landscapes during invasion (Melbourne et al., 2007). Indeed invasions are not uniform across a landscape. For example, they can follow linear landscape features such as rivers or roads (Buckley et al., 2007; Jodoin et al., 2008; Predick and Turner, 2008; Christen and Matlack, 2009; Laurence et al., 2009). Here we investigate the impact of landscape heterogeneity and the presence of landscape features on the eradication of an invasive species.

The main ecological reasons for the failure of control programs seem to be related to the spatial scale of the program being either too large or too small (e.g. species re-invasion from neighboring areas after successful local elimination), the difficulty in detecting an invasive species, and the limited duration of a control program (Mack et al., 2000; Manchester and Bullock, 2000; Myers et al., 2000; Simberloff, 2001; Zavaleta et al., 2001; Nogales et al., 2004; Russell et al., 2005; Cacho et al., 2006; Regan et al., 2006; Howald et al., 2007; Václavík and Meentemeyer, 2009). Although spatial aspects are a component in many of these reasons for failure, very few theoretical studies have considered control programs in an explicitly spatial context (but see Eisinger and Thulke, 2008). Indeed, one important variable for a control strategy is its spatial design. For example, a strategy may be global, as for example in airdrops of pesticides or poison baits (e.g. for moths and rodents, Howald et al., 2007; Bogich et al., 2008) or local, as for example in land-based application of pesticides or local plant removal (Emery and Gross, 2005; Hansen, 2007). 
Factors other than spatial design are important components of a control program. The specificity of a control action towards an invasive species, the ability to detect an invasive species and the ability to efficiently remove invasive individuals once they have been identified must all be considered. For example, a limit in detection ability has been demonstrated in remote sensing studies of invasive weeds, where invasive weeds can only be identified from remote sensing when flower-bract cover exceeds $10 \%$ (Hunt et al., 2007) or when all sites cannot be sampled (Leung and Delaney, 2006). An example of a species specific control action is selective hunting of animals (Courchamp et al., 2003), whereas the use of fire or pesticide can be largely indiscriminate (Knezevic et al., 2004; Emery and Gross, 2005; Hansen, 2007; Howald et al., 2007; Kriticos et al., 2009). Finally, efficiency in the control action will be affected by available resources for supporting the control action and the life history of the invasive. For example, plant taxa in the genus Fallopia have a $20-60 \%$ probability of regenerating from stem segments or rhizomes left in the soil after a control action (Bimova et al., 2003). Invasive species management (be it control or eradication programs) requires significant long-term funding and effort where the above factors are often competing for limited resources (Simberloff, 2001; Marris, 2005; Regan et al., 2006; Mehta et al., 2007; Baxter et al., 2008).

The contributions of the above factors to the overall success of a control program have not previously been evaluated in spatially heterogeneous landscapes. Here, we describe the dynamics of a competitively superior invasive species in a heterogeneous landscape and investigate the success of a control program as a function of the landscape heterogeneity, the spatial scale of an action (applied locally at community or globally, at metacommunity level), the species specificity of the control strategy (targeted, non-targeted), the ease of detecting an invasive species (the detection threshold and the control effort), and the efficiency of invasive removal once they have been detected (removal efficiency). For this, we use a spatially heterogeneous metacommunity model and we document the probability and time taken for the invasive species to either dominate, or be eradicated.

\section{Methods}

\subsection{Invasion in a heterogeneous metacommunity}

With a stochastic metacommunity model, we simulate the dynamics of two species, one native, one invasive, competing for the same limiting resource in a meta-community model composed by 25 habitat patches (communities) arranged in a square grid with absorbing boundaries. In this meta-community, we consider that the invasive species can have a local competitive advantage, $c_{i}$, over the native. This local competitive advantage can vary depending on the distribution of spatial habitats (see later). This competitive advantage can be seen as either (i) a local fecundity advantage over the native species, thus the invasive species produces $\left(1+c_{i}\right)$ times as many offspring per reproductively mature individual compared to the native species or (ii) the invasive species' juvenile survival probability (between birth and dispersal) is $\left(1+c_{i}\right)$ times higher than the native species. This translates into a higher local growth rate for the invasive over the native species. Thus after reproduction the frequency of the invasive species in the habitat $i, p_{i}^{*}$ becomes:

$p_{i}^{*}=\frac{\left(1+c_{i}\right) p_{i}}{1+c_{i} p_{i}}$

where $p_{i}$ is the frequency of adult, reproductively mature invasive species in habitat patch $i$.

After reproduction adults die (generations are not overlapping) and regulation is imposed by the habitat patch's carrying capacity (fixed to $N=100$ individuals), independent of species composition. Drift occurs during local population regulation, simulated by a binomial sample of 100 individuals of the native and invasive species. This yields after binomial sampling the frequency of the invasive species in the habitat $i, p_{i}^{* *}$. During dispersal a proportion $m$ of individuals are replaced at random in each community by the same proportion of individuals from communities within a dispersal distance $d$ (i.e. all communities within a distance $d$ contribute to the immigration pool of community $i$ ). After dispersal the frequency of the invasive species in habitat patch $i$ becomes:

$p_{i}^{* * *}=(1-m) p_{i}^{* *}+\frac{m}{n} \sum_{k=1}^{n} p_{k}^{* *}$

where $n$ is the number of communities located within the dispersal distance.

To sum up, the life cycle is set as (1) adult reproduction and death, (2) juvenile competition, (3) population regulation and (4) dispersal. Note that details on local population dynamics are ignored following the usual metapopulation approach (Hanski, 1999). However, implications of this assumption will be discussed.

Three main landscapes are considered in which the global average competitive advantage, $\bar{c}$ of the invasive species is the same over the metacommunity ( $\bar{c}=0.02$ ) but varies locally (Fig. 1 ). The first ("uniform") assumes a homogeneous landscape in which the invasive species has the same competitive advantage everywhere $\left(c_{i}=\bar{c}=0.02\right)$. The second ("linear") assumes the invasive species has only a competitive advantage along a linear feature $\left(c_{i}=0.1\right)$ and has no competitive advantage elsewhere $\left(c_{i}=0\right)$. Finally, a landscape ("point") in which the invasive species has a strong local advantage that is restricted to one single habitat patch $\left(c_{i}=0.5\right)$ but no advantages elsewhere $\left(c_{i}=0\right)$. Additionally, we consider a second type of heterogeneous landscape ("random") which is an extension of the "uniform" landscape, where the $c_{i}$ value for each habitat patch is drawn from a normal distribution with a mean value $c_{i}=0.02$ and a standard deviation, $\sigma$, in the range of $0-0.04$ (corresponding to a coefficient of variation, $\sigma / c_{i}$, in the range of
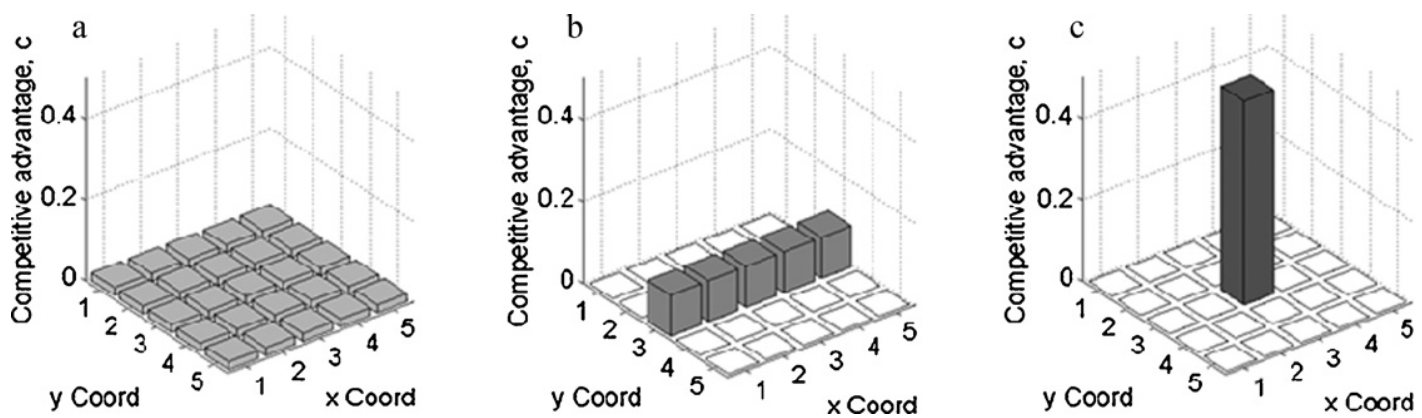

Fig. 1. The three landscapes considered in the model for the growth-rate advantage of the invasive species. (a) Uniform, (b) linear and (c) point. The average competitive advantage across the whole landscape is the same for all three cases $(\bar{c}=0.02)$. 
$0-2)$. As $\sigma$ increases the heterogeneity of the landscape increases, but the heterogeneity of these random landscapes has no spatial structure. These landscapes are therefore equivalent to a uniform landscape with an additional random component.

The values of the competitive advantage used in the model range from 0 to 0.5 . These population growth rates (relative to native species) are conservative since they are at the lower end of observed population growth rates for invasions by birds (Caswell et al., 2003) and plants (Vilà and Weiner, 2004; Ramula et al., 2008). The three main landscape types (uniform, linear and point) capture three gross features of an invasive landscape. The uniform landscape captures the situation where the invasive species is a superior competitor at all locations. The random landscape allows for local variation in this competitive superiority, but the expectation is still that the invasive species is a superior competitor. Examples of complete competitive superiority can be found in aquatic plants such as Myriophyllum spicatum (Moody and Les, 2007) and other hyper-successful plants (Strayer, 2010). The linear landscape captures situations where the competitive superiority of the invasive species is limited to a linear feature, such as a road or a riverbank (Buckley et al., 2007; Jodoin et al., 2008; Predick and Turner, 2008; Christen and Matlack, 2009; William et al., 2009). Finally, the single habitat patch corresponds to an isolated source population of invasive species, such as a newly disturbed habitat that promotes invasive species survival (Predick and Turner, 2008) or hotspots of repeated species introduction (Rahel, 2007).

\subsection{Control effort of the invasive species}

The control effort of the invasive species occurs through mortality imposed after dispersal and before reproduction. Control effort occurs with a probability $e$ and can vary according to the following parameters.

First, control effort can be equally distributed globally "at the meta-community level" (i.e. across the entire grid) or locally applied "at the community level" (i.e. within each grid square). Actions applied at the metacommunity level are indiscriminately applied to all communities in the landscape with a probability $e$ if the invasive has been detected (i.e. if the global frequency of the invasive species is greater than the detection threshold, $F$ ). Actions applied at the community level only concern habitat patches where the invasive species has been identified (i.e. if the local frequency of the invasive species within a patch is greater than the detection threshold, $F$ ). This relates to techniques that can be used against an invasive. Actions at the meta-community level refer to techniques applied at a large scale such as airdrops of pesticides or poison baits (Howald et al., 2007; Bogich et al., 2008) while actions applied at the community level refer to local action such as local plant removal (Emery and Gross, 2005; Hansen, 2007).

Second, control effort can be targeted or not targeted depending on its species specificity. A targeted action will only affect the invasive species, such as selective hunting (Courchamp et al., 2003). Not-targeted control effort will affect both invasive species and native species indiscriminately, such as the use of fire or pesticide (Knezevic et al., 2004; Emery and Gross, 2005; Hansen, 2007; Howald et al., 2007).

Third, we will consider a detection threshold, $F$ that characterizes the frequency of the invasive species above which a control effort starts. This frequency can be evaluated either at the metacommunity or at the community level depending upon the scale of the control effort considered. The frequency of the invasive species at which a control effort starts has strong practical implications. Indeed it has been shown that survey techniques to detect invasive species are often difficult, imprecise and costly (McArdle, 1990; Reed, 1996; Myers et al., 1998; Manchester and Bullock, 2000; Pimentel et al., 2000; Hastings et al., 2005; Regan et al., 2006;
Leung and Delaney, 2006; Howald et al., 2007; Bogich et al., 2008; Václavík and Meentemeyer, 2009). It therefore appears important to evaluate the effect of invasive species frequency before control.

Finally, a control effort can be more or less efficient in removing individuals. To account for this parameter, we introduce the removal efficiency, $q$, defined as the frequency of the invasive species after an eradication action. For a targeted action, the frequency of the invasive species is reduced to a value $q$. For a non-targeted action, all individuals within a community (habitat patch) are eliminated (provided the control effort permits the action to take place). This habitat patch remains empty until re-colonization.

After control, the frequency of the invasive species in habitat patch $i$ becomes

$p_{i}^{* * * *}= \begin{cases}q & \text { with probability } e \text { if } P>F \\ p_{i}^{* * *} & \text { otherwise }\end{cases}$

where $P$ is either the frequency of the invasive species at the metacommunity level for a global control effort, or the frequency of the invasive species at community level for a local control effort (i.e. $P=p_{i}^{* * *}$ ).

\subsection{Simulation set-up}

The invasion probability and time needed for an invasion were evaluated for different dispersal distances $d$ (ranging from 1 to 8 , a value of 1 corresponds to dispersal events occurring only to the nearest-neighbor communities while a value of 8 allows dispersal everywhere in the metacommunity) and migration rates (ranging from $1 \%$ to $50 \%$ of individuals emigrating from a community). To evaluate eradication strategies, we varied the control effort $e$ (ranging from 0 to 0.8 , with the default being zero), the detection threshold $F$ (ranging from 0 to 0.8 , with the default being 0.2 ) and the removal efficiency $q$ (ranging from 0 to 0.1 , with the default being zero, this value corresponds to the residual frequency of invasive species in a community after a control effort).

For each parameter set we ran 10,000 simulations and recorded the probabilities of invasion, eradication and extinction, and the time associated with these events. Invasion was successful when the invasive species had completely displaced the native species. Eradication was successful when the invasive species had been eliminated from the metacommunity. Extinctions occurred if both the invasive and native species were eliminated from the metacommunity. The time to invasion was defined as the number of life-cycles from the start of a simulation until the native species had been entirely removed. Conversely, the time until eradication was defined as the number of life-cycles from the start of a simulation until the invasive species was entirely removed. The time to extinction was defined as the number of life-cycles from the start of a simulation until both the native and the invasive species had been entirely removed from the metacommunity.

Simulations were started with one invasive individual in each community and stopped after 20,000 generations if native and invasive species were still coexisting. Table 1 summarizes the parameters considered.

\section{Results}

\subsection{Invasion in heterogeneous landscape}

Landscape heterogeneity increased invasion probability and time to invasion. The probability that an invasive species replaced the native species increased with landscape heterogeneity but remained relatively constant over the range of dispersal distances, $d$, considered (Fig. 2a and b). The highest invasion probability was obtained with the most heterogeneous landscape (the "point" 
Table 1

Parameters used in the model.

\begin{tabular}{|c|c|c|c|}
\hline Parameters & Name & Range & Default value \\
\hline$d$ & Maximum dispersal distance & $1-8$ & 8 \\
\hline$m$ & Migration rate & $0.001-0.5$ & 0.05 \\
\hline$c_{i}$ & $\begin{array}{l}\text { Local growth-rate advantage of } \\
\text { the invasive species in the ith } \\
\text { patch }\end{array}$ & $0-0.5$ & - \\
\hline$\sigma$ & $\begin{array}{l}\text { Standard deviation of the local } \\
\text { growth-rate advantage of the } \\
\text { invasive species in the uniform } \\
\text { landscape, } c=0.02\end{array}$ & $0-0.04$ & 0 \\
\hline$n$ & $\begin{array}{l}\text { Number of communities that } \\
\text { contribute to the migration pool }\end{array}$ & $2-25$ & 25 \\
\hline e & Control effort & $0-1$ & 0 \\
\hline$F$ & Detection threshold & $0-0.8$ & 0.2 \\
\hline$q$ & Removal efficiency & $0-0.1$ & 0 \\
\hline$N$ & Community carrying capacity & 100 & 100 \\
\hline
\end{tabular}

landscape, mean probability of invasion over all simulations was $79 \%$ ) and the lowest with the uniform landscape (mean probability of invasion over all simulations was 61\%). Adding in a random component of variance, $\sigma$, to the competitive advantage generally increased the invasion probability (Fig. 2b). Thus, heterogeneity increased the invasion probability, be it spatially structured (e.g. point and linear) or spatially random. Increasing landscape heterogeneity also increased the mean number of generations needed for full invasion (Fig. 2c and d). This value was more than twofold higher for the point landscape ( $\sim 1500$ generations) compared to the uniform landscape ( $\sim 600$ generations).

Migration rate, combined with landscape heterogeneity, also affected the invasion probability (Fig. 3). A sufficiently low migration rate will prevent invasion while a sufficiently high migration rates will always remove the effects of landscape heterogeneity by quickly mixing individuals from different local communities. However, intermediate values of migration rate had a relatively weak effect upon the invasion of a species. When migration rate exceeded $m=0.05$, the highest invasion probability was obtained in the "point" landscape, reaching its maximum value, $86 \%$, when migration rate was 0.3 (Fig. 3a). When migration was low $(m<0.05)$ the time to invasion increased with the heterogeneity (Fig. 3c) and the invasive species performed best in the "linear" landscape. There was no significant effect of migration when the landscape was uniform, even when spatial variability was considered (Fig. 3b). The mean time needed for full invasion strongly decreased as migration rate increased (Fig. 3c) or variation in $c_{i}$ decreased (Fig. 3d). The probability of invasion and time until invasion with a uniform, but variable landscape were always less that the results obtained with the linear and point landscape.

\subsection{Control effort}

\subsubsection{Applied globally, at the metacommunity level}

When control effort was applied globally (at the metacommunity level), with no targeting towards the invasive species and with a detection threshold of $20 \%(F=0.2, e>0$, Fig. $4 a)$, the probability of eradicating the invasive species increased with the control effort $e$, reaching unity for $e>0.7$ in all the landscapes. Increasing the control effort parameter, $e$, makes it more likely that local detection of invasive species will result in a control action ( $e=0.7$ gives a $70 \%$ probability that species detection will give rise to control). The time until eradication decreased with increasing $e$, down to 17 generations for $e=0.8$. However, there was a probability that both species went extinct for control efforts exceeding $e=0.4$. Complete eradication of the invasive species was achieved with a control effort of $e \approx .8$, but this result was combined with a $20 \%$ probability of eradicating the native species. Extinction time was much longer for the native species than for the invasive species (Fig. $4 \mathrm{~b}$ and $\mathrm{c}$ ). Increasing the detection threshold $F$ decreased the probability of eradicating the invader (Table 2 ) and increased time until eradica-
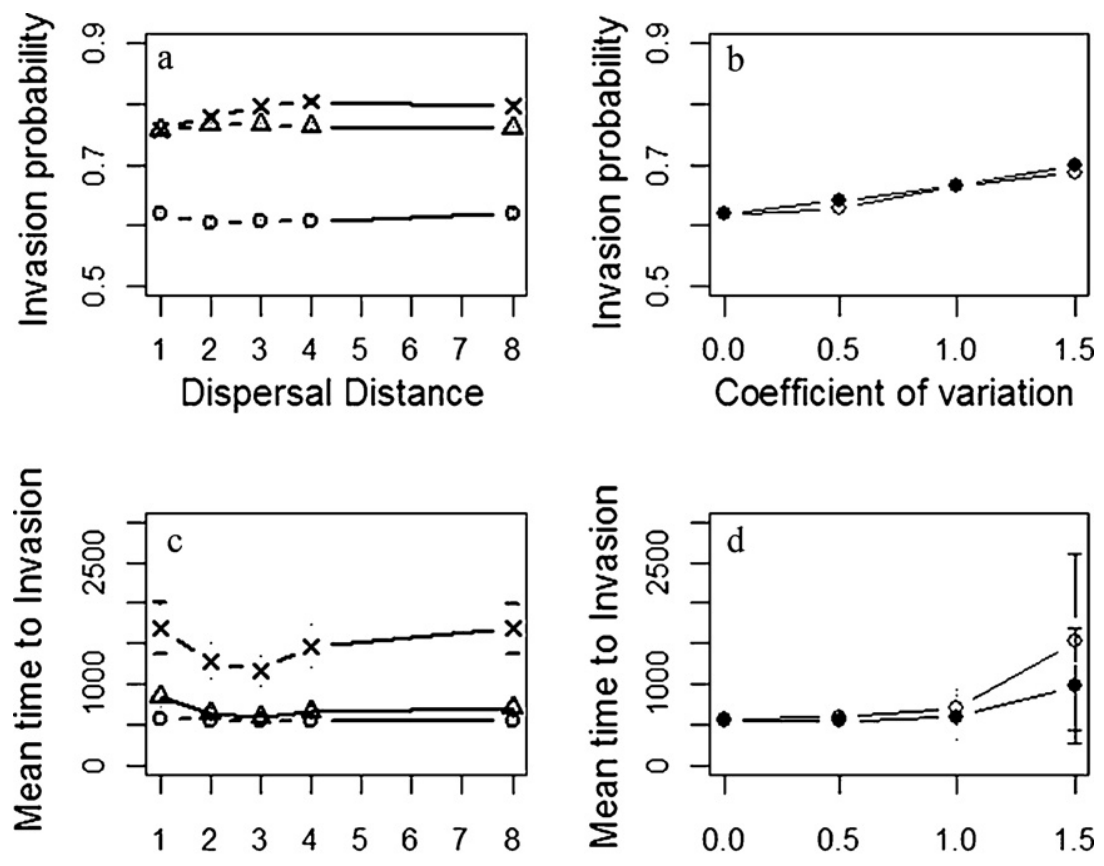

Dispersal Distance

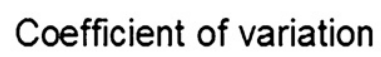

Fig. 2. (a and c) The invasion probability and invasion time as a function of dispersal range, $d$ for a uniform (circles), linear (triangles) and point (crosses) landscape. (b and d) The invasion probability and invasion time in the random landscape as a function of landscape heterogeneity (coefficient of variation for competitive advantage, $\sigma / c$ ) for dispersal range $d=1$ (black circles) and $d=8$ (white circles). Migration rate is set to $m=0.05$ and initially one individual invasive species is present in each local community. Error bars show the inter quartile range from 10,000 simulations. 

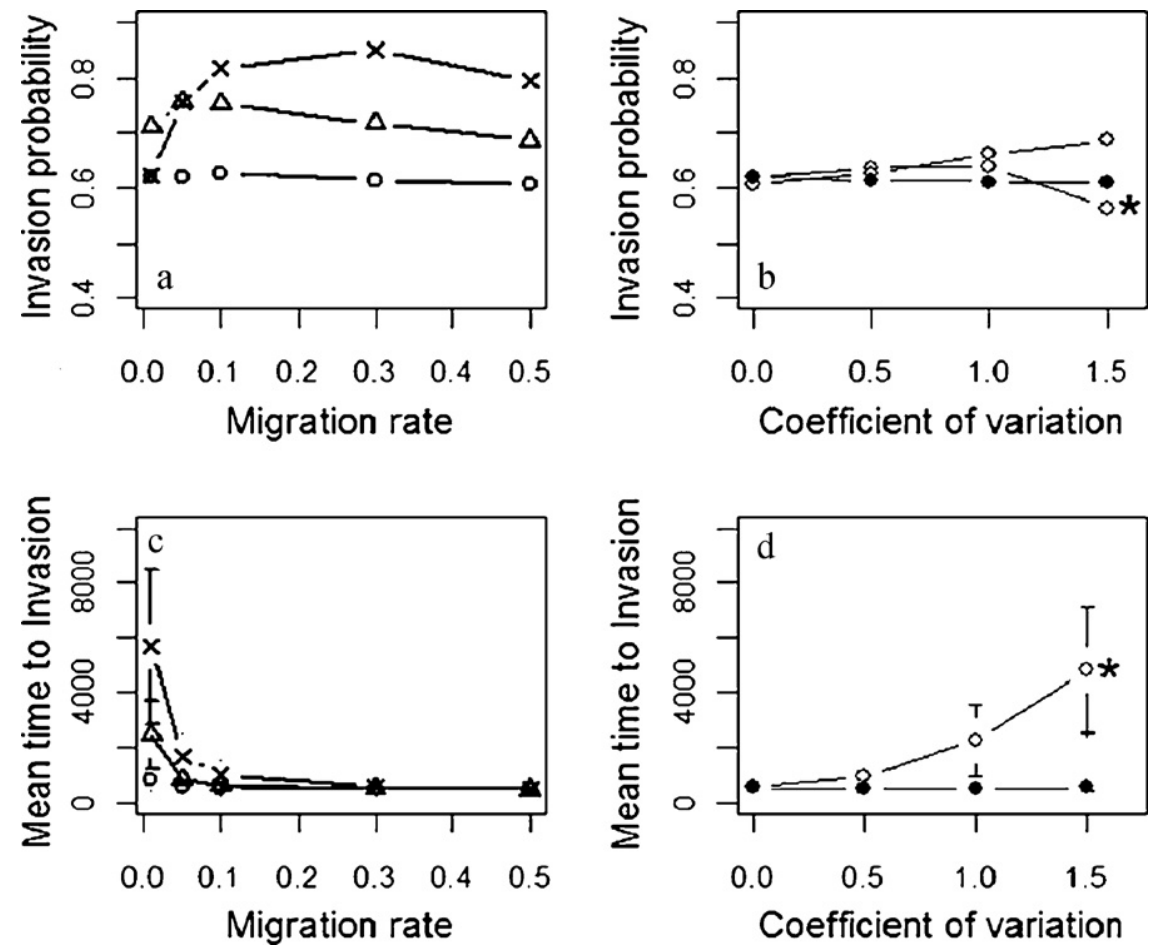

Fig. 3. (a and c) The invasion probability and invasion time as a function of migration rate, $m$ for a uniform (circles), linear (triangles) and point (crosses) landscape. (b and d) The invasion probability and invasion time as a function of landscape heterogeneity (coefficient of variation for competitive advantage, $\sigma / c$ ) for three values of migration rate: low $m=0.01$ (white circles), moderate $m=0.05$ (grey circles) and high $m=0.5$ (black circles). Dispersal distance is set to $d=1$, and initially one individual invasive species is present in each local community. Error bars show the inter quartile range from 10,000 simulations. * $23 \%$ of the simulations were not used to calculate invasion probability because after 20,000 generations the invasion was still in progress (i.e. coexistence of natives and invasive).
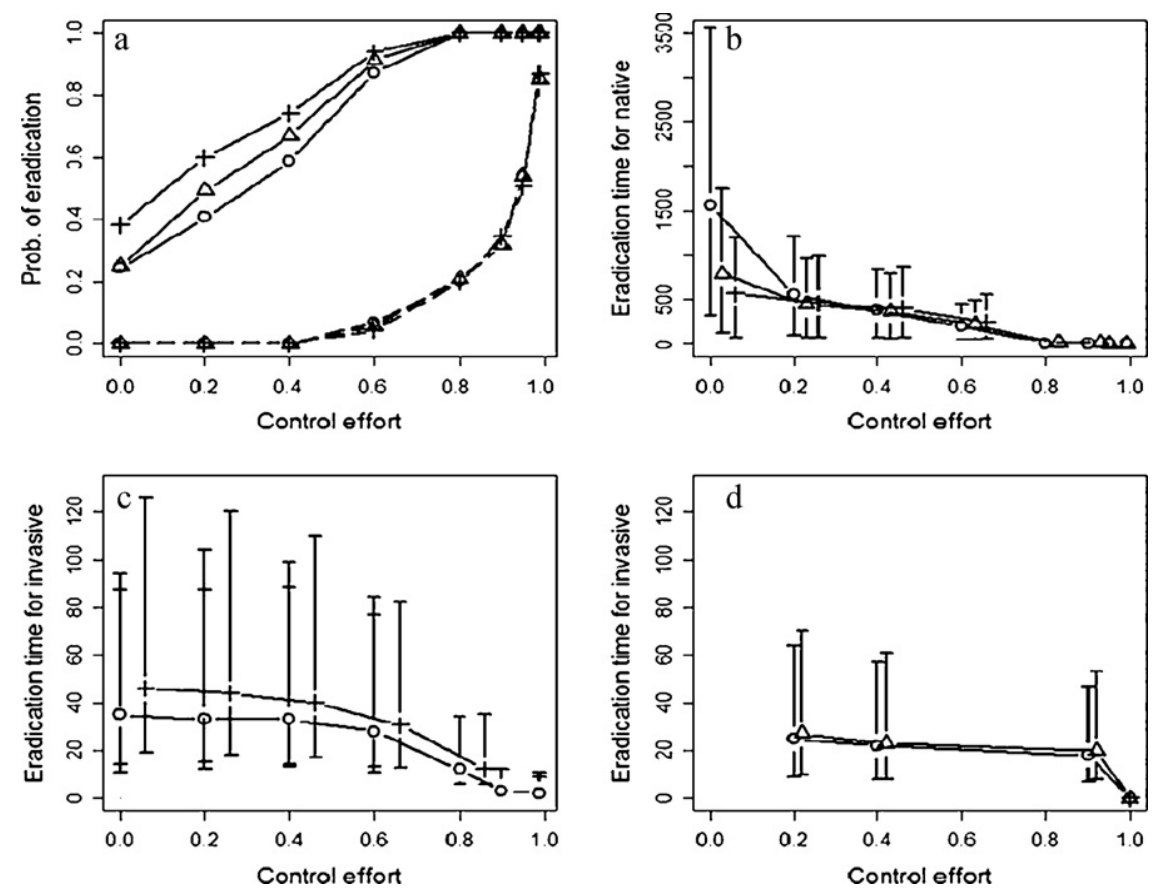

Fig. 4. The eradication probability and the time until eradication as a function of control effort, $e$, and landscape heterogeneity (uniform $=$ crosses, linear $=$ triangles, and point = circles). (a) Probability of eradicating the invasive species (solid line) and probability of eradicating both native and invasive species (dashed line) non-targeted control program applied at metacommunity level (errors are smaller than symbols). (b and c) The median times to eradication of native and invasive species conditional on eradication (for simulations from panel a). (d) The median time to eradication of the invasive species for a targeted control program applied at community level. Error bars show the inter quartile range from 10,000 simulations with default parameter values (see Section 2). 
Table 2

The probability of eradicating the invasive/native species as a function of the control strategy (described in Section 2 ), the control effort (e), detection threshold $(F)$ and removal efficiency $(q)$. Three main outputs are possible depending on the eradication probability of each species: invasion, eradication and coexistence. Each result is from 10,000 simulations in a uniform landscape.

\begin{tabular}{|c|c|c|c|c|c|c|c|}
\hline & & \multirow[t]{2}{*}{ Control strategy } & & \multicolumn{4}{|l|}{$e$} \\
\hline & & & & 0.2 & 0.4 & 0.6 & 0.8 \\
\hline \multirow{8}{*}{ Global } & \multirow{3}{*}{ Non-targeted } & \multirow{8}{*}{$q=0$} & $F=0$ & $0.62 / 0.38$ & $0.77 / 0.33$ & $0.95 / 0.1$ & $1 / 0.4$ \\
\hline & & & $F=0.2$ & $0.6 / 0.4$ & $0.74 / 0.26$ & $1 / 0.1$ & $1 / 0.2$ \\
\hline & & & $F=0.8$ & $0.44 / 0.66$ & $0.51 / 0.49$ & $1 / 0.2$ & $1 / 0.2$ \\
\hline & \multirow{5}{*}{ Targeted } & & $F=0$ & $1 / 0$ & $1 / 0$ & $1 / 0$ & $1 / 0$ \\
\hline & & & $F=0.2$ & $1 / 0$ & $1 / 0$ & $1 / 0$ & $1 / 0$ \\
\hline & & & $F=0.8$ & $1 / 0$ & $1 / 0$ & $1 / 0$ & $1 / 0$ \\
\hline & & & $q=0$ & $1 / 0$ & $1 / 0$ & $1 / 0$ & $1 / 0$ \\
\hline & & & $q=0.1$ & $1 / 0$ & $1 / 0$ & $1 / 0$ & $1 / 0$ \\
\hline \multirow{8}{*}{ Local } & \multirow{4}{*}{ Non-targeted } & & $F=0$ & $1 / 0$ & $1 / 0$ & $1 / 0$ & $1 / 0$ \\
\hline & & & $F=0.2$ & $1 / 0$ & $1 / 0$ & $1 / 0$ & $1 / 0$ \\
\hline & & & $F=0.8$ & $0.37 / 0.0$ & $0.36 / 0.0$ & $0.37 / 0.0$ & $0.36 / 0.0$ \\
\hline & & & $F=0$ & $1 / 0$ & $1 / 0$ & $1 / 0$ & $1 / 0$ \\
\hline & \multirow{4}{*}{ Targeted } & $q=0$ & $F=0.2$ & $1 / 0$ & $1 / 0$ & $1 / 0$ & $1 / 0$ \\
\hline & & & $F=0.8$ & $0.4 / 0$ & $0.38 / 0$ & $0.37 / 0$ & $0.37 / 0$ \\
\hline & & $F=0$ & $q=0$ & $1 / 0$ & $1 / 0$ & $1 / 0$ & $1 / 0$ \\
\hline & & & $q=0.1$ & $1 / 0$ & $1 / 0$ & $1 / 0$ & $1 / 0$ \\
\hline
\end{tabular}

Table 3

The median value of time until eradication of the invasive species (conditional on successful eradication, Table 1 as a function of control strategy (described in the methods), control effort $(e)$, detection threshold $(F)$ and removal efficiency $(q)$. Quartiles are shown in brackets. Each result is from 10,000 simulations in a uniform landscape.

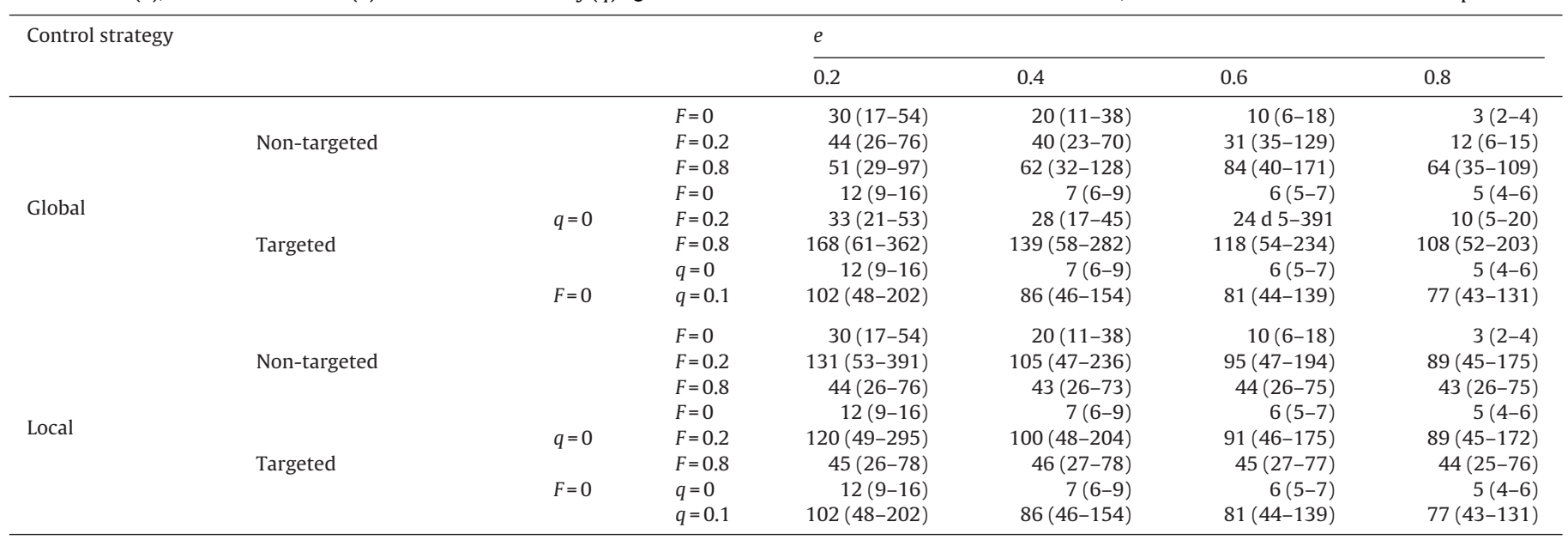

tion (Table 3 ), but did not affect the critical control effort $(e \approx 0.7)$ above which eradication was assured.

Targeting the control effort towards the invasive species ensured complete eradication of the invader within 30 generations on average, irrespective of the control effort and landscape heterogeneity considered here (Fig. 4c, Tables 2 and 3). Increasing the detection threshold $(F)$ increased time until eradication, which showed a five-fold increase as one passed from $F=0$ to $F=0.2$. Imperfect removal efficiency $(q>0)$ produced the same qualitative results, but with a stronger effect on time until eradication. For instance, failing to remove $10 \%$ of a local invasive species population had a much stronger effect on time until eradication compared to the situation where the detection threshold was increased from $0 \%$ to $20 \%$ (Table 3 ). Interestingly, when control effort was strong $(e>0.6)$ at the metacommunity level, no effect of landscape heterogeneity was observed (Fig. 4a).

\subsubsection{Applied locally, at community level}

In all our simulations, applying a control effort locally, at the community level guaranteed eradication of the invasive species if the detection threshold, $F$, was lower than $20 \%$ (Table 2). This result applied for both targeted and non-targeted strategies, although the time to eradication was shorter with targeted actions (Table 3).
However, above a critical detection threshold $(F \approx 0.3)$, control effort applied at the metacommunity level failed to eradicate the invasive species in $60 \%$ of cases and no complete invasion was recorded, so that native and invasive species coexisted. This result was observed for both non-targeted and targeted actions. Increasing $F$ further did not affect coexistence, but increased the relative frequency of the invasive species. When control effort was applied at the community level, no effect of landscape heterogeneity was detected (Fig. 4c).

\section{Discussion}

\subsection{Invasion in heterogeneous landscape}

Invasion success as well as time until invasion increases with landscape heterogeneity. Heterogeneity matters because it creates a few habitat patches where local competitive advantages markedly promote an invader, which reduce the initial chance of the invader being eliminated from the community due to demographic stochasticity. Once an invasive species is established in a favorable local community, these communities act as sources from which invaders can colonize the whole landscape. Thus, invasion takes longer (because invaders do not benefit from competitive 
advantages over most of the landscape) but occurs with more certainty. Invasion failures mostly occurred during the first steps of invasion, when invaders were rare and demographic stochasticity was strong enough to override small competitive advantages.

Dispersal distances do not have a strong effect upon the probability and time until invasion because the major process that promotes invasion is the local increase in abundance of the invasive species. Migration rate has a greater effect than dispersal distance, primarily on the time until invasion. At low migration rates, when the within-community dynamics are much faster than the spatial dynamics, the linear landscape (intermediate heterogeneity) gives the highest invasion probability. In this situation, the invasive species increases in abundance in communities where it has a high competitive advantage, which then act as a source of invasive species into the rest of the meta-community. However, the invasion process as a whole is very slow, which increases the exposure of the invasive species to stochastic local extinctions. In this case, intermediate heterogeneity (the linear landscape) favors the invasion as it provides a spatially extended source of invasive individuals that is less susceptible to stochastic extinctions. When migration is strong, the invasive species quickly spreads, and spatial differences in invasive species abundance are quickly removed. So high migration rates promote homogeneity, and reduce the effect of any heterogeneity in competitive ability. Therefore, intermediate migration rates give the highest invasion probabilities in heterogeneous landscapes (linear and point) because they strike a compromise, allowing extinct communities to be recolonized while allowing an invasive species' to escape the threat of demographic stochasticity in communities where its competitive advantage is high.

The benefits of a heterogeneous landscape to an invading species vanish with increasing control efforts, because increasing the control effort reduces the effective size of the meta-community, which in turn strengthens the force of demographic stochasticity over variations in competitive advantage. Eradication success is lower when control is applied globally, at metacommunity level, because locally some communities can be above the detection threshold without triggering control if the frequency of the invasive species across the entire metacommunity is below the detection threshold.

\subsection{Control effort}

Increasing control effort (e) increases the probability of eradicating an invasive species, but has surprisingly little effect on time until eradication (Fig. 4). From our results (Fig. 4a), control effort can be fine-tuned to ensure a high eradication probability for the invasive while minimizing the extinction risk of the native. But high control efforts may seriously threaten native species when applied indiscriminately (Fig. 4a). As expected, non-targeted actions applied at the metacommunity level should be avoided because they risk eliminating both the native and the invasive species. Since a nonzero detection threshold induces a frequency-dependent survival function on the invasive species (lower survival when its frequency exceeds the detection threshold), coexistence is favored when control effort is applied at the community level with a nonzero detection threshold. This result is in agreement with studies of species diversity in metacommunities under local disturbances (Connell, 1978; Huston, 1979; Sousa, 1979; Chesson and Huntly, 1997; Questad and Foster, 2007; Raghu et al., 2007).

Our results confirm that cost-effective actions require early interventions, when the frequency of the invasive species is still low (Myers et al., 1998; Byers et al., 2002; Puth and Post, 2005). Targeted control is particularly efficient when applied at a low detection threshold $(F<0.2)$. Indeed, assuming elimination of $80 \%$ of individuals $(e=0.8)$ a targeted control applied either locally or globally (at community or metacommunity level) allowed the eradication of an invasive species in less than 5 generations (median value, when $F=0$ ). Increasing the detection threshold to $F=0.2$ increased the time until eradication to 10 generations (control at the metacommunity level) or 89 generations (control at the community level). Increasing the detection threshold introduces a time-delay between initial invasion and the onset of a control action. This delay depends on the time taken for the invasive species to reach a frequency, $F$. This value is a function of the local competitive advantage but also of the metacommunity dynamics and should be carefully considered during management intervention.

Eradication efficiency, however, appears more important than detection. Allowing the proportion of invaders surviving control $(q)$ to increase from $0 \%$ to $10 \%$ increased the time to eradication from 5 to 77 generations for control at both the community and metacommunity level $(F=0, e=0.8)$. Early detection shortens the time until eradication of the invasive species only if the control program is efficient (low $q$ value). This time until eradication is more sensitive to eradication efficiency (a low $q$ ) than to early detection (a low $F$ ). These results confirm that early detection is a waste of resources if efficiency of the eradication action is not guaranteed (Harwood et al., 2009). This has practical implications since technical and financial constraints in the early detection of invasive species limit the success of an eradication program (Myers et al., 1998; Manchester and Bullock, 2000; Pimentel et al., 2000; Hastings et al., 2005; Regan et al., 2006; Howald et al., 2007; Bogich et al., 2008).

\subsection{Implications of model assumptions}

Our work does not include many details of specific case studies but is general enough to be applicable to numerous taxa. We concentrate upon the effect of each strategy independently from the others, although multiple strategies can be used in control programs (e.g. Courchamp et al., 2003). We consider the case of complete eradication of an invasive species, which for some species will be extremely difficult, but our qualitative results remain if we replace the eradication criterion with a critical frequency that the invasive species must be reduced to (data not shown). The scale of our study area, with its 25 patches, is relatively small, but our results are expected to apply to far larger areas provided the local community size does not change greatly. The local community size $(N=100)$ is the main determinant of the strength of demographic stochasticity. If local community size is increased then demographic stochasticity is weakened and the average growthrate advantage of an invasive species must also weaken in order for the effects of spatial heterogeneity to be seen. We ignore local demography by assuming that prior to every round of reproduction the number of individuals in a patch has reached carrying capacity. If newly recolonized patches do not immediately reach carrying capacity, then demographic stochasticity will be stronger because the community will spend longer at low abundances. This will weaken the competitive advantage of an invasive species, but it is not expected to remove the effect of spatial heterogeneity as long as competitive advantage remains stronger than demographic stochasticity. We investigated the impact of heterogeneity with reduced carrying capacities ( $N=20$ and 50 , results not shown) with no change in our qualitative conclusions. Our conclusions are thus likely to remain the same if local demography is fully incorporated.

Our model assumes that the competitive advantage and the efficiency of the control action are constant through time. These assumptions may not be true over the full course of an invasion as competitive advantage may decrease with time and depend upon the frequency of the invasive species (Mooney and Cleland, 2001; Bøhn et al., 2004; Meiners, 2007; Morrison et al., 2007; SebertCuvillier et al., 2007; White and Shurin, 2007; Dlugosch and Parker, 2008; Hierro et al., 2009). 


\section{Conclusion}

Recent reviews have highlighted the need to explore the effects of habitat heterogeneity upon the mechanisms of invasion and coexistence (Hastings et al., 2005; Melbourne et al., 2007). Here, we demonstrate that spatial heterogeneity promotes invasion but also increases the time until invasion, and can reduce the probability of eradicating an invasive species if the control effort is light. Coexistence can also be promoted if control effort is applied only when the invasive species has reached a fairly high frequency (imperfect detection of the invasive species), by inducing a frequency-dependent disturbance regime. However, the time taken to globally eradicate an invasive species is unaffected by the heterogeneity of the environment. Therefore, optimal control strategies drawn from studies on uniform environments (e.g. Regan et al., 2006; Shea et al., 2006; Mehta et al., 2007; Bogich et al., 2008) should be applicable.

The importance of detecting an invasive species early, before it has reached a high abundance, has been emphasized as an important aspect of an efficient eradication program (e.g. Moody and Mack, 1988; Myers et al., 1998). Recently, the practical issue of balancing the benefits of early detection against the costs of this action have been analyzed (Cacho et al., 2006; Mehta et al., 2007; Baxter et al., 2008; Bogich et al., 2008). Such studies show that the optimal effort towards early detection is modified by factors such as the ease of detection, the population growth rate of the invasive species and the costs incurred by not controlling the invasive species. Our study goes further by quantifying the impact of early detection on eradication success, and contrasts its effect when detection is performed locally (community) or globally (metacommunity). Additionally we show that the importance of early detection must be balanced against removal efficiency. Early detection of an invasive species is only worthwhile if is followed through with an efficient local control effort.

\section{Acknowledgements}

This work was supported by the grants PZ00P3-121702 to S.V. and 3100AO-108100 to N.P. both from the Swiss National Science Foundation.

\section{References}

Baxter, P.W.J., Sabo, J.L., Wilcox, C., McCarthy, M.A., Possingham, H.P., 2008. Cost-effective suppression and eradication of invasive predators. Conservation Biology 22, 89-98.

Bimova, K., Mandak, B., Pysek, P., 2003. Experimental study of vegetative regeneration in four invasive Reynoutria taxa (Polygonaceae). Plant Ecology 166, 1-11.

Bogich, T.L., Liebhold, A.M., Shea, K., 2008. To sample or eradicate? A cost minimization model for monitoring and managing an invasive species. Journal of Applied Ecology 45, 1134-1142.

Bøhn, T., Sandlund, O.T., Amundsen, P.A., Primicerio, R., 2004. Rapidly changing life history during invasion. Oikos 106, 138-150.

Buckley, Y.M., Bolker, B.M., Rees, M., 2007. Disturbance, invasion and re-invasion: managing the weed-shaped hole in disturbed ecosystems. Ecology Letters 10, 809-817.

Byers, J.E., Reichard, S., Randall, J.M., Parker, I.M., Smith, C.S., Lonsdale, W.M., Atkinson, I.A.E., Seastedt, T.R., Williamson, M., Chornesky, E., Hayes, D., 2002. Directing research to reduce the impacts of nonindigenous species. Conservation Biology $16,630-640$.

Cacho, O.J., Spring, D., Pheloung, P., Hester, S., 2006. Evaluating the feasibility of eradicating an invasion. Biological invasions 8, 903-917.

Caswell, H., Lenski, R.E., Neubert, M.G., 2003. Demography and dispersal: life table response experiments for invasion speed. Ecology 84, 1968-1978.

Chesson, P., 2000. General theory of competitive coexistence in spatially-varying environments. Theoretical Population Biology 58, 211-237.

Chesson, P., Huntly, N., 1997. The roles of harsh and fluctuating conditions in the dynamics of ecological communities. The American Naturalist, 150.

Christen, D.C., Matlack, G.R., 2009. The habitat and conduit functions of roads in the spread of three invasive plant species. Biological Invasions 11, 453-465.

Connell, J.H., 1978. Diversity in tropical rain forests and coral reefs. Science 199, 1302-1310.
Courchamp, F., Chapuis, J.-L., Pascal, M., 2003. Mammal invaders on islands: impact, control and control impact. Biological Reviews 78, 347-383.

Dlugosch, K.M., Parker, I.M., 2008. Invading populations of an ornamental shrub show rapid life history evolution despite genetic bottlenecks. Ecology Letters 11, 701-709.

Eisinger, D., Thulke, H.-H., 2008. Spatial pattern formation facilitates eradication of infectious diseases. Journal of Applied Ecology 45, 415-423.

Emery, S.M., Gross, K.L., 2005. Effects of timing of prescribed fire on the demography of an invasive plant, spotted knapweed Centaurea maculosa. Journal of Applied Ecology 42, 60-69.

Hansen, M.J, 2007. Evaluating management strategies and recovery of an invasive grass (Agropyron cristatum) using matrix population models. Biological Conservation 140, 91-99.

Hanski, I., 1999. Metapopulation Ecology. Oxford University Press, Oxford.

Harwood, T.D., Xu, X., Pautasso, M., Jeger, M.J., Shaw, M.W., 2009. Epidemiological risk assessment using linked network and grid based modelling: Phytophthora ramorum and Phytophthora kernoviae in the UK. Ecological Modelling 220, 3353-3361.

Hastings, A., Cuddington, K., Davies, K.F., Dugaw, C.J., Elmendorf, S., Freestone, A.L., Harrison, S., Holland, M., Lambrinos, J., Malvadkar, U., Melbourne, B.A., Moore, K., Taylor, C., Thomson, D., 2005. The spatial spread of invasions: new developments in theory and evidence. Ecology Letters 8, 91-101.

Hierro, J.L., Eren, O., Khetsuriani, L., Diaconu, A., Torok, K., Montesinos, D., Andonian, K., Kikodze, D., Janoian, L., Villarreal, D., Estanga-Mollica, M.E., Callaway, R.M., 2009. Germination responses of an invasive species in native and non-native ranges. Oikos 118, 529-538.

Holt, R.D., Keitt, T.H., Lewis, M.A., Maurer, B.A., Taper, M.L., 2005. Theoretical models of species' borders: single species approaches. Oikos 108, 18-27.

Howald, G., Donlan, C.J., Galvan, J.P., Russell, J.C., Parkes, J., Samaniego, A., Wang, Y., Veitch, D., Genovesi, P., Pascal, M., Saunders, A., Tershy, B., 2007. Invasive rodent eradication on islands. Conservation Biology 21, 1258-1268.

Hunt, E.R., Daughtry, C.S.T., Kim, M.S., Williams, A.E.P., 2007. Using canopy reflectance models and spectral angles to assess potential of remote sensing to detect invasive weeds. Journal of Applied Remote Sensing, 1.

Huston, M., 1979. A general hypothesis of species diversity. The American Naturalist $113,81-101$

Jodoin, Y., Lavoie, C., Villeneuve, P., Theriault, M., Beaulieu, J., Belzile, F., 2008. Highways as corridors and habitats for the invasive common reed Phragmites australis in Quebec, Canada. Journal of Applied Ecology 45, 459-466.

Knezevic, S.Z., Smith, D., Kulm, R., Doty, D., Kinkaid, D., Goodrich, M., Stolcpart, R., 2004. Purple Loosestrife (Lythrum salicaria) control with herbicides: singleyear application. Weed Technology 18, 1255-1260 Levine JM (2008) biological invasions. Current Biology 18, R57-R60.

Kriticos, D.J., Watt, M.S., Withers, T.M., Leriche, A., Watson, M.C., 2009. A processbased population dynamics model to explore target and non-target impacts of a biological control agent. Ecological Modelling 220, 2035-2050.

Laurence, W.F., Goosem, M., Laurance, S.G.W., 2009. Impacts of roads and linear clearings on tropical forests. Trends in Ecology and Evolution 24, 659-669.

Leung, B., Delaney, D.G., 2006. Managing sparse data in biological invasions: a simulation study. Ecological Modelling 198, 229-239.

Levine, J.M., 2008. Biological invasions. Current Biology 18, R57-R60.

Mack, R.N., Simberloff, D., Lonsdale, W.M., Evans, H., Clout, M., Bazzaz, F.A., 2000. Biotic invasions: causes, epidemiology, global consequences and control. Ecological Applications 10, 689-710.

Manchester, S.J., Bullock, J.M., 2000. The impacts of non-native species on UK biodiversity and the effectiveness of control. Journal of Applied Ecology 37, 845-864.

Marris, E. 2005. Shoot to kill. Nature 438, 272-273.

McArdle, B.H., 1990. When are rare species not there? Oikos 57, 276-277.

Mehta, S.V., Haight, R.G., Homans, F.R., Polasky, S., Venette, R.C., 2007. Optimal detection and control strategies for invasive species management. Ecological Economics 61, 237-245.

Meiners, S.J., 2007. Native and exotic plant species exhibit similar population dynamics during succession. Ecology 88, 1098-1104.

Melbourne, B.A., Cornell, H.V., Davies, K.F., Dugaw, C.J., Elmendorf, S., Freestone, A.L., Hall, R.J., Harrison, S., Hastings, A., Holland, M., Holyoak, M., Lambrinos, J., Moore, K., Yokomizo, H., 2007. Invasion in a heterogeneous world: resistance, coexistence or hostile takeover? Ecology Letters 10, 77-94.

Moody, M.L., Les, D.H., 2007. Geographic distribution and genotypic composition of invasive hybrid watermilfoil (Myriophyllum spicatum x M-sibiricum) populations in North America. Biological invasions 9, 559-570.

Moody, M.E., Mack, R.N., 1988. Controlling the spread of plant invasions: the importance of nascent foci. Journal of Applied Ecology 25, 1009-1021.

Mooney, H.A., Cleland, E.E., 2001. The evolutionary impact of invasive species. Proceedings of the National Academy of Sciences of the USA 98, 5446-5451.

Morrison, S.A., Macdonald, N., Walker, K., Lozier, L., Shaw, M.R., 2007. Facing the dilemma at eradication's end: uncertainty of absence and the Lazarus effect. Frontiers in Ecology and the Environment 5, 271-276.

Mouquet, N., Loreau, M., 2002. Coexistence in metacommunities: the regional similarity hypothesis. The American Naturalist 159, 420-426.

Myers, J.H., Savoie, A., Randen, E., 1998. Eradication and pest management. Annual Review of Entomology 43, 471-491.

Myers, J.H., Simberloff, D., Kuris, A.M., Carey, J.R., 2000. Eradication revisited: dealing with exotic species. Trends in Ecology and Evolution 15, 316-320.

Nogales, M., Martin, A., Tershy, B., Donlan, C.J., Veitch, D., Puerta, N., Wood, B., Alonso, J., 2004. A review of feral cat eradication on islands. Conservation Biology 18 , 310-319. 
Pimentel, D., Lach, L., Zuniga, R., Morrison, D., 2000. Environmental and economic costs of nonindigenous species in the United States. Bioscience 50, 53-65.

Predick, K.I., Turner, M.G., 2008. Landscape configuration and flood frequency influence invasive shrubs in floodplain forests of the Wisconsin River (USA). Journal of Ecology 96, 91-102.

Puth, L.M., Post, D.M., 2005. Studying invasion: have we missed the boat? Ecology Letters 8, 715-721.

Questad, E.J., Foster, B.L., 2007. Vole disturbances and plant diversity in a grassland metacommunity. Oecologia 153, 341-351.

Raghu, S., Dhileepan, K., Scanlan, J.C., 2007. Predicting risk and benefit a priori in biological control of invasive plant species: a systems modelling approach. Ecological Modelling 208, 247-262.

Rahel, F.J., 2007. Biogeographic barriers, connectivity and homogenization of freshwater faunas: it's a small world after all. Freshwater Biology 52, 696-710.

Ramula, S., Knight, T.M., Burns, J.H., Buckley, Y.M., 2008. General guidelines for invasive plant management based on comparative demography of invasive plant populations. Journal of Applied Ecology 45, 1124-1133.

Reed, J.M., 1996. Using statistical probability to increase confidence of inferring species extinction. Conservation Biology 10, 1283-1285.

Regan, T.J., McCarthy, M.A., Baxter, P.W.J., Panetta, F.D., Possingham HP, 2006. Optimal eradication: when to stop looking for an invasive plant. Ecology Letters 9 759-766.

Russell, J.C., Towns, D.R., Anderson, S.H., Clout, M.N., 2005. Intercepting the first rat ashore. Nature 437, 1107.

Sebert-Cuvillier, E., Paccaut, F., Chabrerie, O., Endels, P., Goubet, O., Decocq, G., 2007. Local population dynamics of an invasive tree species with a complex life-history cycle: a stochastic matrix model. Ecological Modelling 201, 127-143.
Seno, H., Koshiba S, 2005. A mathematical model for invasion range of population dispersion through a patchy environment. Biological Invasions 7, 757-770.

Shea, K., Chesson, P., 2002. Community ecology theory as a framework for biological invasions. Trends in ecology and evolution 17, 170-176.

Shea, K., Sheppard, A., Woodburn, T., 2006. Seasonal life-history models for the integrated management of the invasive weed nodding thistle Carduus nutans in Australia. Journal of Applied Ecology 43, 517-526.

Simberloff, D., 2001. Eradication of island invasives: practical actions and results achieved. Trends in Ecology and Evolution 16, 273-274.

Simberloff, D., 2005. The politics of assessing risk for biological invasions, the USA as a case study. Trends in Ecology and Evolution 20,216-222.

Sousa, W.P., 1979. Disturbance in marine intertidal boulder fields: the nonequilibrium maintenance of species diversity. Ecology 60, 1225-1239.

Strayer, D.L., 2010. Alien species in fresh waters: ecological effects, interactions with other stressors, and prospects for the future. Freshwater Biology 55, 152-174.

Theoharides, K.A., Dukes, J.S., 2007. Plant invasion across space and time: factors affecting nonindigenous species success during four stages of invasion. New Phytologist 176, 256-273.

Václavík, T. Meentemeyer, R.K., 2009. Invasive species distribution modeling (iSDM): are absence data and dispersal constraints needed to predict actual distributions? Ecological Modelling 220, 3248-3258.

Vilà, M., Weiner, J., 2004. Are invasive plant species better competitors than native plant species? Evidence from pair-wise experiments. Oikos 105, 229-238.

White, L.F., Shurin, J.B., 2007. Diversity effects on invasion vary with life history stage in marine macroalgae. Oikos 116, 1193-1203.

Zavaleta, E.S., Hobbs, R.J., Mooney, H.A., 2001. Viewing invasive species removal in a whole-ecosystem context. Trends in Ecology and Evolution 16, 454-459. 